\title{
Drastic Improvements in Air Quality in Ecuador during the COVID-19 Outbreak
}

\author{
Rasa Zalakeviciute ${ }^{1,2^{*}}$, Renne Vasquez ${ }^{2}$, Daniel Bayas², Adrian Buenano², Danilo Mejia ${ }^{3}$, \\ Rafael Zegarra ${ }^{3}$, Valeria Diaz ${ }^{4}$, Brian Lamb ${ }^{5}$ \\ ${ }^{1}$ Grupo de Biodiversidad Medio Ambiente y Salud (BIOMAS), Universidad de Las Americas, Quito - EC 170125, Ecuador \\ ${ }^{2}$ Universidad de Las Americas, Quito - EC 170125, Ecuador \\ ${ }^{3}$ Carrera de ingeniería ambiental, Facultad de Ciencias Químicas, Universidad de Cuenca, Cuenca 010203, Ecuador \\ ${ }^{4}$ Air Quality Monitoring Network, Secretariat of the Environment, Municipality of the Quito Metropolitan District, Calle \\ Rio Coca, Quito - EC 170125, Ecuador \\ ${ }^{5}$ Laboratory for Atmospheric Research, Washington State University, Pullman, WA 99163, USA
}

\begin{abstract}
In the beginning of 2020, the global human population encountered the pandemic of novel coronavirus disease 2019 (COVID-19). Despite social and economic concerns, this epidemiologic emergency has brought unexpected positive consequences for environmental quality as human activities were reduced. In this paper, the impact of restricted human activities on urban air quality in Ecuador is investigated. This country implemented a particularly strict set of quarantine measures at the very dawn of the exponential growth of infections on March 17, 2020. As a result, significant reductions in the concentrations of $\mathrm{NO}_{2}(-68 \%), \mathrm{SO}_{2}(-48 \%), \mathrm{CO}(-38 \%)$ and $\mathrm{PM}_{2.5}(-29 \%)$ were measured in the capital city of Quito during the first month of quarantine. This large drop in air pollution concentrations occurred at all the monitoring sites in Quito, serving as a valuable proof of the anthropogenic impact on urban air quality. The spatial evolution of atmospheric pollution using observed surface and satellite data, showed different results for the two major cities: Quito and Guayaquil. While the population in Quito adhered to the quarantine measures immediately, in the port city of Guayaquil, quarantine measures were slow to be adopted and, thus, the effect on air quality in Guayaquil occurred more slowly. This lag could have a considerable cost to the mortality rate in the port city, not only due to the spread of the disease but also due to the poor air quality. Overall, the air quality data demonstrate how quickly air quality can improve when emissions are reduced.
\end{abstract}

Keywords: COVID-19; Urban air pollution; Quarantine measures.

\section{INTRODUCTION}

In the first three months of 2020, the human population of the world encountered a colossal challenge - a global pandemic of coronavirus disease 2019 (COVID-19). This infectious disease is caused by the novel severe acute respiratory syndrome coronavirus 2 (SARS-CoV-2). The first news of the exponential infection rate of SARS-CoV-2, spreading to thousands of people in a period of weeks and rapidly causing countless deaths, started arriving from China in January 2020. Then, quickly, by the end of March 2020, the same exponential growth of infection was replicated in almost every country of the world (Worldometer, 2020). Some countries rigorously adopted social distancing measures by putting in quarantine entire cities at the first few identified cases. Meanwhile, others chose to wait until the

\footnotetext{
* Corresponding author.

E-mail address: rasa.zalake@gmail.com
}

numbers reached well into thousands to apply mitigation actions, if at all. For the significance of this study, one of the countries implementing the stricter scenario is Ecuador (pop. 16.6 million people). The capital Quito suspended all non-essential activities when eight infected individuals were reported on March 17, 2020. However, in Guayaquil, the biggest port city in Ecuador, the local population failed to adopt the quarantine measures quickly. Reported infections quickly grew from 111 to about 1082 individuals nationally in one week, but most of these were in Guayaquil (Servicio Nacional de Gestion de Riesgos y Emergencias, 2020). This rapid escalation placed Ecuador at the top of the list of Latin American countries with the highest infection and death rates (Cabrera and Kurmanaev, 2020; Worldometer, 2020).

Despite the calamities caused to human health by the coronavirus outbreak, this crisis has brought unexpected positive consequences for air quality and the environment. Relentless population growth and urbanization in the past decades have produced continuously worsening air quality conditions in many cities in developing countries (UN, 2015; Limb, 2016; WHO, 2016). Criteria atmospheric pollutants 
(carbon monoxide $(\mathrm{CO})$, nitrogen oxides $\left(\mathrm{NO}\right.$ and $\left.\mathrm{NO}_{2}\right)$, sulfur dioxide $\left(\mathrm{SO}_{2}\right)$, ozone $\left(\mathrm{O}_{3}\right)$ and particulate matter $(\mathrm{PM})$ ), predominantly fine particulate matter (with aerodynamic diameter $\leq 2.5 \mu \mathrm{m}, \mathrm{PM}_{2.5}$ ), are known for causing negative effects on respiratory and cardiovascular health (Pope and Dockery, 2012; Lelieveld et al., 2015; U.S EPA, 2018). These negative health impacts exacerbate the symptoms of COVID-19 (Gardiner, 2020; Wu et al., 2020). Worldwide implementations of precautionary quarantine, namely closures of factories, shopping centers, restrictions on travel and transportation, have resulted in a considerable reduction of emissions of air pollutants as well as greenhouse gases (Cho, 2020; Wang et al., 2020). In contrast to other research, a recent study in Tehran reported an increase in $\mathrm{PM}_{2.5}$ and $\mathrm{PM}_{10}$ concentrations due to a rise in private car use during the quarantine (Faridi et al., 2020). In different regions of China, studies have shown that strict COVID-19 control policies significantly reduced concentrations of criteria pollutants except for ozone (Chen et al., 2020; Xu et al., 2020). The most significant decrease in $\mathrm{CO}(20-36 \%)$ and $\mathrm{NO}_{2}$ $(30-52.8 \%)$ concentrations were correlated with a reduction of emissions due to economic and transport restrictions (Filonchyk et al., 2020; Xu et al., 2020). The National Aeronautics and Space Administration (NASA) and the European Space Agency released satellite images that show a significant $(10-30 \%)$ reduction in nitrogen dioxide $\left(\mathrm{NO}_{2}\right)$ concentrations, between the months of January and February in eastern and central China, and between February and March in northern Italy (ESA, 2020; NASA, 2020). Chinese data also showed the lowest average concentrations of $\mathrm{PM}_{2.5}$ particulate matter since 2014 (Cho, 2020; Wang et al., 2020), confirmed by (Xu et al., 2020). However, as expected, the pollution levels have returned to previous levels when economic activities are resumed (Filonchyk et al., 2020).

The economic slowdown due to the COVID-19 outbreak has also caused at least a $25 \%$ decline in carbon dioxide $\left(\mathrm{CO}_{2}\right)$ emissions in late January in China, representing a $6 \%$ reduction in global emissions (Cho, 2020). As a result, during the last three weeks of February, China emitted 150 million metric tons less of $\mathrm{CO}_{2}$ than last year on the same dates. A recent study showed that global $\mathrm{CO}_{2}$ emissions in March 2020 were $7 \%$ lower than the same time last year, mostly due to the decrease in industrial use of fossil fuels, especially coal (Safarian et al., 2020).

At this point, during the first months of social distancing and mitigation actions, there is still a lack of published scientific studies concerning changes in air quality in the cities of Latin America. Prata et al. (2020) reported results for Brazil which only focused on the impact of meteorological parameters on COVID-19 pandemic. Prata et al. (2020) found a negative linear relationship between temperatures and daily cumulative confirmed cases of COVID-19. This relationship was also reported for Malaysia (Suhaimi et al., 2020), but not in studies in Norway and Singapore (Menebo, 2020; Pani et al., 2020). Therefore, the objective of this paper is to evaluate the impact of the reduced human activities on urban air pollution in the Ecuadorian capital, Quito. The case of Quito is additionally more interesting, as a range of strict social measures were implemented early on; and as a result, there is already one month of quarantine data on atmospheric conditions from this high elevation Andean city.

\section{METHODS}

\section{Study Site}

Ecuador is one of the less urbanized countries in South America, the second most urbanized continent of our planet (UN, 2019). The capital city Quito is located on a narrow plateau wrapping around the Pichincha volcano (elev. 4,800 meters above sea level (m.a.s.l.)) in the Andes cordillera. The city is the highest constitutional capital of the world with an average elevation of 2,815 m.a.s.l. (EMASEO, 2011). The rapidly growing metro area now occupies $4,218 \mathrm{~km}^{2}$ with more than 2.2 million people (INEC, 2011). Due to the use of poor quality fuels, the city struggles with long-term air pollution problems (Zalakeviciute et al., 2017). The city has a mild spring-like climate with two distinct seasons: wet (September-May) and dry (June-August) (Zalakeviciute et al., 2018a).

Within the city mayor's office, the Secretariat of Environment has managed an air quality network since 2004 to monitor the concentrations of atmospheric criteria pollutants and meteorological parameters. Nine monitoring stations are distributed across the city in representative areas varying in elevation, population density, intensities of traffic and industrial activities. In this investigation, data from seven study sites were analyzed: Guamani (elev. 3,066 m.a.s.l., coord. 78 33'5"W, 0¹9'51"S), Los Chillos (elev. 2,453 m.a.s.1, coord. 78 27'36"W, $0^{\circ} 18^{\prime} 00^{\prime \prime} \mathrm{S}$ ), Camal (elev. 2,840 m.a.s.1, coord. 78 $30^{\prime} 36^{\prime \prime} \mathrm{W}, 0^{\circ} 15^{\prime} 00^{\prime \prime S}$ ), Belisario (elev. 2,835 m.a.s.l, coord. $78^{\circ} 29^{\prime} 24^{\prime \prime} \mathrm{W}, 0^{\circ} 10^{\prime} 48^{\prime \prime} \mathrm{S}$ ), Centro (elev. 2,820 m.a.s.l, coord. 78 $30^{\prime} 36^{\prime \prime} \mathrm{W}, 0^{\circ} 13^{\prime} 12^{\prime \prime} \mathrm{S}$ ), Cotocollao (elev. 2,739 m.a.s.l, coord. $78^{\circ} 29^{\prime} 50^{\prime \prime} \mathrm{W}, 0^{\circ} 6^{\prime} 28^{\prime \prime} \mathrm{S}$ ) and Carapungo (elev. 2,660 m.a.s.1, coord. 78 26'50"W, 05'54"S) (see Fig. 1).

\section{Quito Air Quality Monitoring}

At each site, air quality monitoring equipment were positioned on the roofs of buildings, in agreement with the requirements set by the Environmental Protection Agency of the United States (U.S. EPA). To measure the concentrations of CO, ThermoFisher Scientific 48i instruments, based on infrared absorption (EPA No. RFCA-0981-054), were used. For $\mathrm{SO}_{2}$, ThermoFisher Scientific 43i high level $\mathrm{SO}_{2}$ analyzers were used. This method is based on ultraviolet florescence (EPA No. EQSA-0486-060). For O 3 , ThermoFisher Scientific 49i ozone analyzers based on ultraviolet absorption (EPA No. EQOA-0880-047) were used. For $\mathrm{NO}_{2}$, ThermoFisher Scientific $42 \mathrm{i} \mathrm{NO}_{\mathrm{x}}$ analyzers were used. This method is based on chemiluminescence method (EPA No. RFNA-1289074). Finally, to measure the concentrations of fine particulate matter - $\mathrm{PM}_{2.5}$, Thermo Scientific FH62C14-DHS continuous ambient particulate monitors 5014i were used. This method is based on a beta ray attenuation method (EPA No. EQPM0609-183).

To acquire meteorological data, complete weather stations with automatic sensors were used. To measure wind speed and direction MetOne instruments were used. Thies Clima equipment were used to measure relative humidity, 


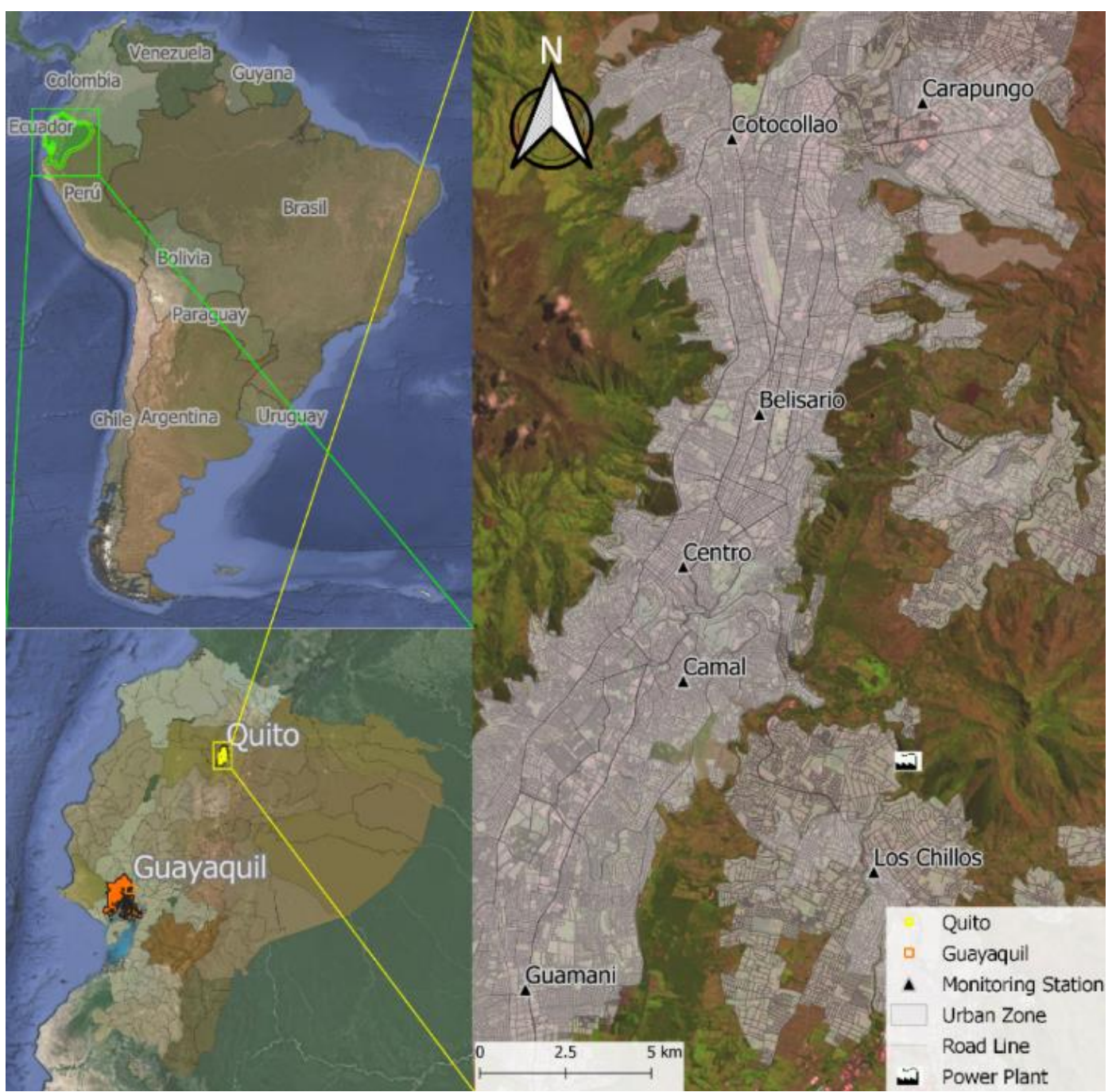

Fig. 1. Map of the study sites distributed in the Ecuadorian capital, Quito.

temperature and precipitation. Finally, solar radiation parameters were measured with Kipp \& Zonen radiometer and pressure with Vaisala equipment.

\section{Sentinel 5P}

The tropospheric concentration $\left(\mathrm{mol} \mathrm{m}^{-2}\right)$ columns of gases used in this research project are products of the TROPOMI instrument on board the Sentinel - precursor (S5P). This satellite carries instruments for the measurement of various pollutants such as $\mathrm{NO}_{2}, \mathrm{CO}, \mathrm{SO}_{2}, \mathrm{CH}_{4}$ and $\mathrm{O}_{3}$ (Veefkind $e t$ al., 2012; Zheng et al., 2019). For our analysis, the L3 level images, provided by the Google Engine (GGE) platform, were used.

\section{Data}

The COVID-19 case count for Ecuador was acquired from the Worldometer (https://www.worldometers.info/cor onavirus/) webpage.

The atmospheric pollution and meteorological data were compiled into four-week, hourly and diurnal averages during the periods prior and during the COVID-19 quarantine. For illustrative purposes, hourly $\mathrm{NO}_{2}, \mathrm{SO}_{2}, \mathrm{PM}_{2.5}$ and $\mathrm{CO}$ concentrations were processed as 24-hour averages starting January 2020. February 2020 data were considered as "normal" conditions, with a usual human activity, and were compared with the pollution levels during the first four weeks of the quarantine March 17-April 12, 2020. All data processing and graphics were performed using Microsoft Excel (MS Office) and Igor Pro (Wavemetrics) softwares. Maps of the city pollution were created using Inverse distance weighting in QGIS open source software.

The S5P satellite data resolution of tropospheric concentration $\left(\mathrm{mol} \mathrm{m} \mathrm{m}^{-2}\right.$ ) columns is $1 \mathrm{~km}^{2}$ per pixel. Knowing that S5P captures total column products of trace gases, daily images of total column of $\mathrm{NO}_{2}$ and tropospheric $\mathrm{SO}_{2}$ from the Royal Netherlands Meteorological Research Institute (KNMI) were used for March 9-31, 2020 (Xue et al., 2020). For this study, daily images were separated into three groups: 9-15 March 2020 one week before quarantine and two first weeks of quarantine March 16-22 and 23-30, 2020. Raster analysis tools were used to obtain the weekly averages. For this study the Google Engine (GGE) platform was used which allows to download L3 level products, GGE uses HARP commands which provides images. 


\section{RESULTS AND DISCUSSION}

\section{COVID-19 Quarantine Timeline in Quito, Ecuador}

A series of quarantine measures were progressively implemented in Ecuador within the first two weeks of a quick escalation of COVID-19 cases (see Fig. 2(a)). On the $16^{\text {th }}$ of March 2020, strict mandatory mitigation measures, focused on a social distancing, were communicated by the national government to the public of Ecuador. At this point there were already 111 confirmed cases, mostly concentrated in the port city of Guayaquil, with no reported cases of deaths in the country (Worldometer, 2020). The next day those measures were successfully applied by the local government in Quito. All city transportation was cancelled, with the exception of the taxi and food/medication delivery services. The use of private vehicles was limited to only essential tasks, such as food and medication purchases. The operation of all businesses, except banks, food stores and pharmacies, was prohibited. All restaurants, theatres, and other public activities were banned by the law. As these measures were implemented, there were some intentions to disobey them, including some protesting activities. These were especially frequent in the port city of Guayaquil. Thus, on Saturday, 21 March 2020, the curfew rule was applied nationally from 19:00 to 5:00, in anticipation of possible weekend festivities. If disobeyed, this rule implied a jail-time punishment. As numbers surpassed 1000 of infected cases on 23 March 2020, additional measures were implemented to further control the use of private vehicles. Vehicle usage was limited, based on the last number of the license plate, allowing circulation only every second day for essential tasks, like food and medication purchases. Furthermore, a stricter curfew was adopted on March 25, 2020 from 14:00 to 5:00, as the number of deaths started rising quickly due to the saturation of limited-capacity hospitals in the country. These measures might seem excessive, when compared to the strategies implemented by other countries, however, at that point, most of the extreme quarantine conditions were reported from the developed and rich in resources countries, and even those were struggling with high daily mortality (e.g., 600-700 cases in Spain and Italy) (Worldometer, 2020). Finally, starting April 5, 2020, private transportation was even further restricted to circulation allowed once per week (based on license plate) for essential shopping, and completely forbidden on the weekends (Fig. 2). There were still essential services allowed, like garbage, gas and food delivery services, even during the curfew hours. But people faced monetary fines, confiscation of their vehicle throughout the quarantine and even jail-time, if caught breaking the law. The circulation between the cities and provinces were strictly forbidden as well since the beginning of the quarantine.

\section{Concentrations of Criteria Pollutants in Quito}

To demonstrate the contrast in urban air pollution due to the COVID-19 mitigation measures in Quito, 24-hour allsites average $\mathrm{NO}_{2}, \mathrm{SO}_{2}, \mathrm{PM}_{2.5}$ and $\mathrm{CO}$ concentrations are presented in Fig. 3 for January 1-April 12, 2020. It can be easily distinguished that the concentrations of the four criteria pollutants began to decrease on March 13, 2020,
Friday before the official implementation of the quarantine measures (starting Tuesday, March 17, 2020, see Fig. 2(a), blue shaded area). This suggests that even before the official quarantine, people started self-isolating, as the number of COVID-19 cases started rising with the first reported death on March 13, 2020 (Fig. 2(b)). A slight increase in concentrations of criteria pollutants can be noted on Monday, March 16, 2020, before the first regulation is applied. However, an overall decreasing trend can be clearly seen (see Fig. 2). Interestingly, while the gaseous pollution levels decreased, $\mathrm{PM}_{2.5}$ concentrations displayed more variability (Fig. 2(c)). This might be due to the fact that even though the anthropogenic emissions were reduced, variable wind speeds could produce varying levels of windblown dust especially during the second week of quarantine (23-29 March 2020) (Fig. 2(c)). Wind direction patterns within the city are quite complex due to the complex terrain. However, we did not observe significant changes in wind direction patterns (not shown) during the quarantine compared to before the quarantine. While the concentrations of the gaseous pollutants reflected a large reduction of anthropogenic activities, the particle pollution levels result from a combination of emissions from anthropogenic activities and dust resuspension. This was also supported by visual observations of hazy skies during the second week of the quarantine, coinciding with windier conditions. The windblown dust appears to be a predominant factor in $\mathrm{PM}_{2.5}$ concentration peaks during these unusual conditions. Finally, as the weather was drier and sunnier, there is an increased possibility of fires, which were also observed in the area. During the last week of the observation period, there were extremely rainy conditions (April 11, 2020) which reduced the particulate resuspension (Fig. 2(d)).

The comparative analysis between average concentrations of $\mathrm{NO}_{2}, \mathrm{SO}_{2}, \mathrm{CO}$ and $\mathrm{PM}_{2.5}$ for the month before the COVID-19 outbreak (February 2020) and during the first four weeks of COVID-19 quarantine (17 March-12 April 2020) across all seven sites are presented in Fig. 3. The results show a strong reduction in average concentrations of four studied criteria pollutants: $\mathrm{NO}_{2}(68 \%), \mathrm{SO}_{2}(48 \%), \mathrm{CO}$ $(38 \%)$ and $\mathrm{PM}_{2.5}(29 \%)$. This large drop in air pollution concentrations was observed at all of the monitoring sites (Figs. 3(a)-3(d)). This is a clear demonstration of the effect of reduced anthropogenic activities on urban air quality. $\mathrm{PM}_{2.5}$ and $\mathrm{CO}$ concentrations were reduced, while $\mathrm{NO}_{2}$ and $\mathrm{SO}_{2}$ concentrations decreased to levels close to zero, especially in the more residential parts of the city (e.g., Cotocollao). However, there is still some evidence of anthropogenic activity in the business districts of Belisario, which includes banks, pharmacies, major shopping centers, and of Los Chillos, which is a suburban residential district with a thermoelectric power plant, see Fig. 1). The change in $\mathrm{NO}_{2}$ levels is higher than those reported in other global cities, ranging from $16 \%$ to $53 \%$ (Chen et al., 2020; Filonchyk et al., 2020; Xu et al., 2020), similarly, the reduction in levels for CO (12-36\%), $\mathrm{PM}_{2.5}(14-50 \%)$ and $\mathrm{SO}_{2}(12-52.5 \%)$ in Quito are also in the higher range compared to other global cities, which is probably due to the strictness of the measures in Ecuador.

The change in local pollution levels due to the COVID-19 

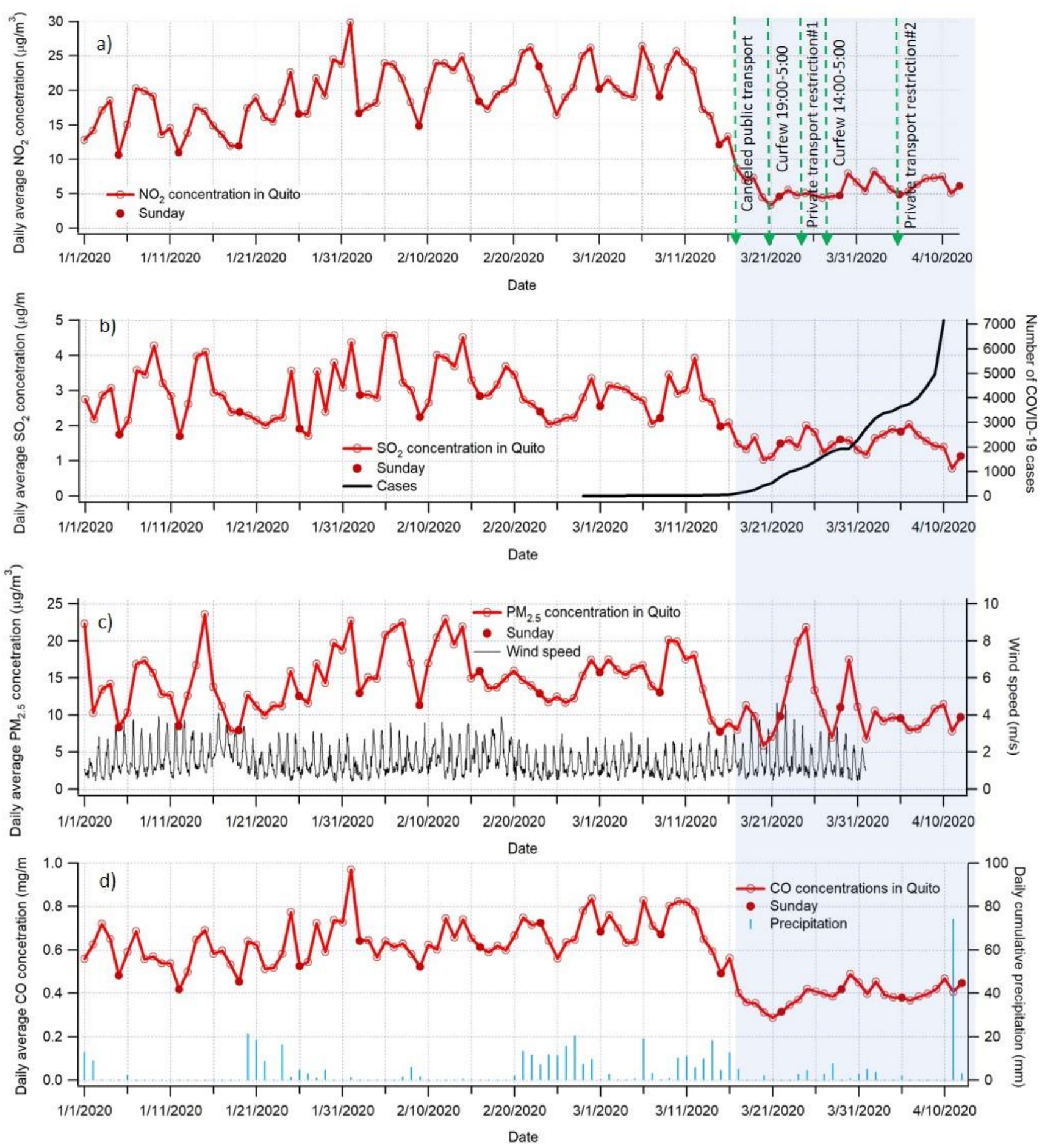

Fig. 2. 24-hour average concentrations for January 1-April 12, 2020 for: a) $\mathrm{NO}_{2}$, b) $\mathrm{SO}_{2}$, c) $\mathrm{PM}_{2.5}$ and d) CO. Blue shaded area indicates the period of COVID-19 quarantine. National quarantine measures (green dotted lines) are displayed in the panel (a). COVID-19 number of infections in Ecuador (black line) are displayed on the right axis of (b). Hourly wind speed data are added on the right axis of (c). Cumulative 24-hour precipitation is displayed on the right axis of (d).

quarantine measures can be also seen in the spatial distribution maps (Figs. 3(e)-3(1)). Four-week averages are shown for February and March 17-April 12, 2020 for $\mathrm{NO}_{2}, \mathrm{SO}_{2}, \mathrm{CO}$ and $\mathrm{PM}_{2.5}$ concentrations in the metropolitan area of Quito. The most notable change can be seen for $\mathrm{NO}_{2}$, the combustion marker for diesel and gasoline engines (Ban-Weiss et al., 2008; Park et al., 2019). During normal conditions, this pollutant was at its highest levels $\left(28-30 \mu \mathrm{g} \mathrm{m}^{-3}\right)$ in the central areas of the city, while it was less prominent (8$21 \mu \mathrm{g} \mathrm{m}^{-3}$ ) in the residential parts of the city (Fig. 3(e)). During the quarantine, $\mathrm{NO}_{2}$ varied from 3 to $8 \mu \mathrm{g} \mathrm{m}^{-3}$, with the minimum concentrations in the residential areas of Quito 
(Fig. 3(i)). Similarly, high reductions were observed for $\mathrm{SO}_{2}$ in all urban areas due to the quarantine measures (Figs. 3(f) and 3(j)). During February of 2020, the concentrations of $\mathrm{SO}_{2}$

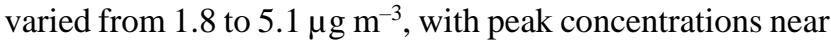
the thermoelectric power plant, in the southern valley of the city (Fig. 3(f)). In Quito, southeasterly winds prevail, due to the equatorial easterlies moving around an old Ilalo volcano, on the east side of the city and encountering the Pichincha volcano on the west side. Therefore, $\mathrm{SO}_{2}$ concentrations consistently decrease moving northwards away from the power a)

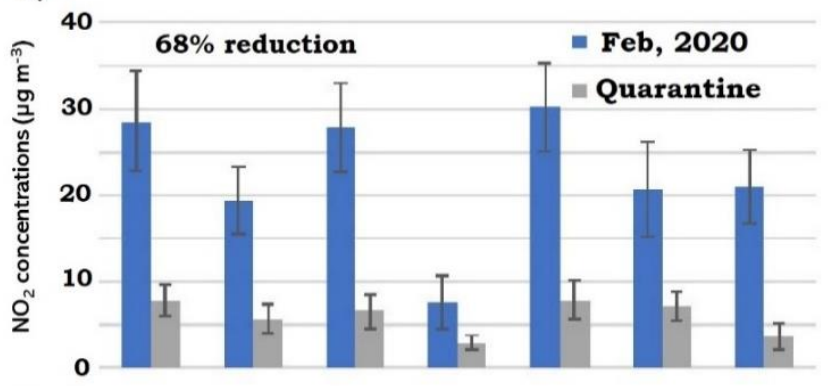

b)

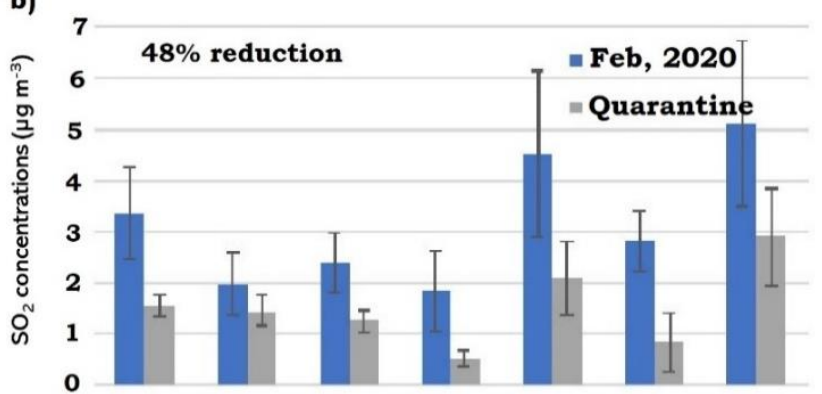

c)

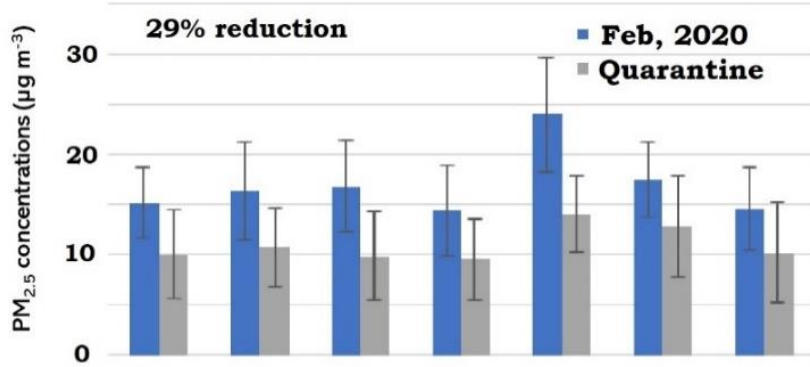

d)

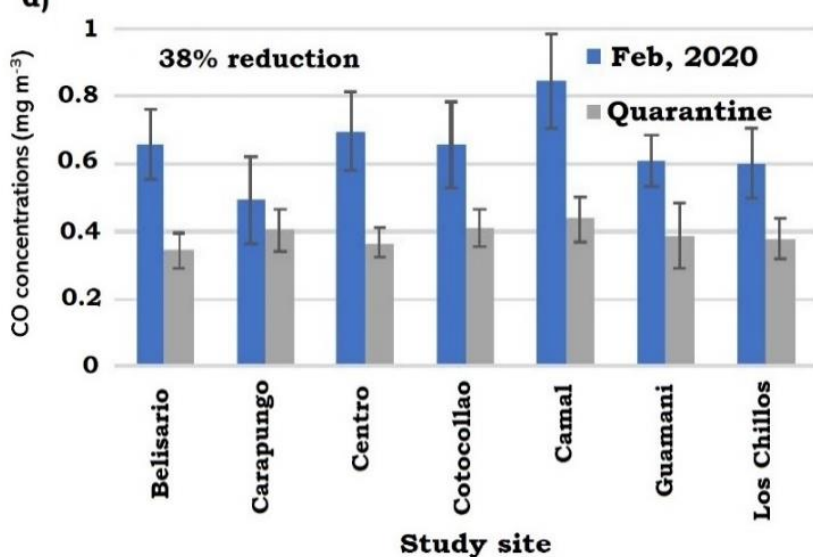

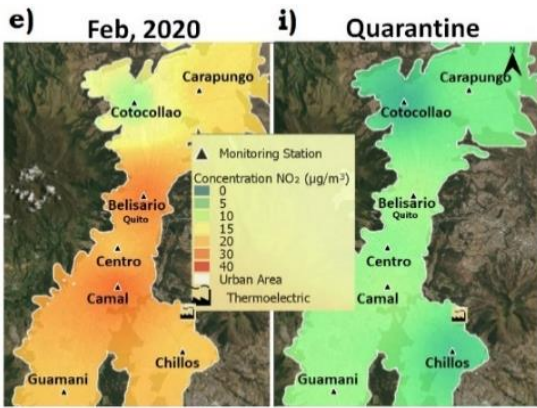
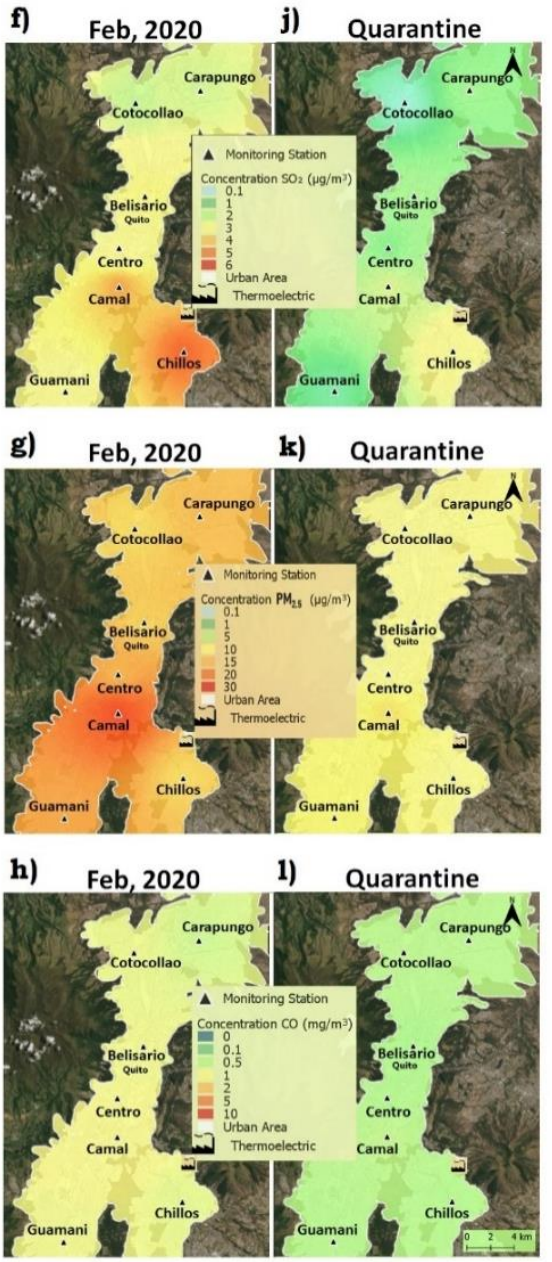

Fig. 3. Four-week average $\mathrm{NO}_{2}, \mathrm{SO}_{2}, \mathrm{PM}_{2.5}$ and $\mathrm{CO}$ concentrations for February 2020 (Feb, 2020) and March 17-April 12, 2020 (period of COVID-19 quarantine measures) in Quito. Comparative bar plot analysis between sites for: a) $\mathrm{NO}_{2}$, b) $\mathrm{SO}_{2}$, c) $\mathrm{PM}_{2.5}$, and d) $\mathrm{CO}$ concentrations. Error bars indicate standard deviation. Spatial analysis is included between the two sets of four weeks: e) and i) for $\mathrm{NO}_{2}, \mathrm{f}$ ) and j) for $\mathrm{SO}_{2}, \mathrm{~g}$ ) and $\mathrm{k}$ ) for $\mathrm{PM}_{2.5}$, and h) and l) for $\mathrm{CO}$ concentrations evolution due to the quarantine measures. 
plant. Even during the quarantine, the highest concentrations of $\mathrm{SO}_{2}$ were found near the power plant $\left(2.9 \mu \mathrm{g} \mathrm{m}^{-3}\right)$ and decreased northwards $\left(0.5 \mu \mathrm{g} \mathrm{m}^{-3}\right)$ (Fig. 3(j)). The reduction of $\mathrm{SO}_{2}$ during the quarantine was approximately $50 \%$, which may be due to the diminished electricity use and also reduced emissions from public transportation, the principal pollution source in this urban area (Zalakeviciute et al., 2017, 2018b).

As previously discussed (Fig.3(c)), the reduction of $\mathrm{PM}_{2.5}$ concentrations due to the quarantine measures was smaller compared to the gaseous pollutants. This may be explained by the increased solar radiation causing windier conditions during the second and third weeks of the quarantine. Even with a great reduction in transportation, there were elevated $\mathrm{PM}_{2.5}$ concentrations in the second and third weeks of quarantine (Fig. 2(c)). During the last week of quarantine, the $\mathrm{PM}_{2.5}$ concentrations decreased as there were more precipitation events accompanied by stricter private vehicle regulation (Fig. 2(d)). The highest concentrations during February occurred in the outskirts of the city in the industrial districts $\left(24 \mu \mathrm{g} \mathrm{m}^{-3}\right.$ ) (Fig. 3(g)), as previously reported (Zalakeviciute et al., 2018a). During the quarantine, those areas were also more polluted $\left(14 \mu \mathrm{g} \mathrm{m}^{-3}\right)$, although at much lower levels (Fig. 3(k)).
Finally, the concentrations of $\mathrm{CO}$ decreased from 0.49 $0.85 \mathrm{mg} \mathrm{m}^{-3}$ during February to $0.34-0.44 \mathrm{mg} \mathrm{m}^{-3}$ during the first four weeks of quarantine (Figs. 3(h) and (l)). This lesser change may be due to the relatively high global background levels of CO (Miller, 2015) upon which is superimposed local CO levels. This also helps explain the low spatial variability of this pollutant across the city. In general, CO levels were highest around the central trafficbusy areas of the city.

\section{$\mathrm{NO}_{2}$ and $\mathrm{SO}_{2}$ Satellite Data for Ecuador}

Satellite data for Ecuador are presented for $\mathrm{NO}_{2}$ and $\mathrm{SO}_{2}$ one week before the COVID-19 quarantine and during the first two weeks of the quarantine in Fig. 4. Here we aimed to study the spatial evolution of the air pollution in relation to the implementation of the protective measures in the country. For both pollutants, the concentrations were reduced during the quarantine in both the major cities: Guayaquil and Quito. Similar pollution behavior was reported in 10 cities in China where, due to the pandemic, there was a restriction in mobility and industry, with a considerable decrease in $\mathrm{NO}_{2}$ and $\mathrm{SO}_{2}$ concentrations (Wang et al., 2020). Likewise, it is again confirmed that $\mathrm{NO}_{2}$ demonstrated a greater decrease in concentrations due to the cessation of transportation
09-15/03/2020
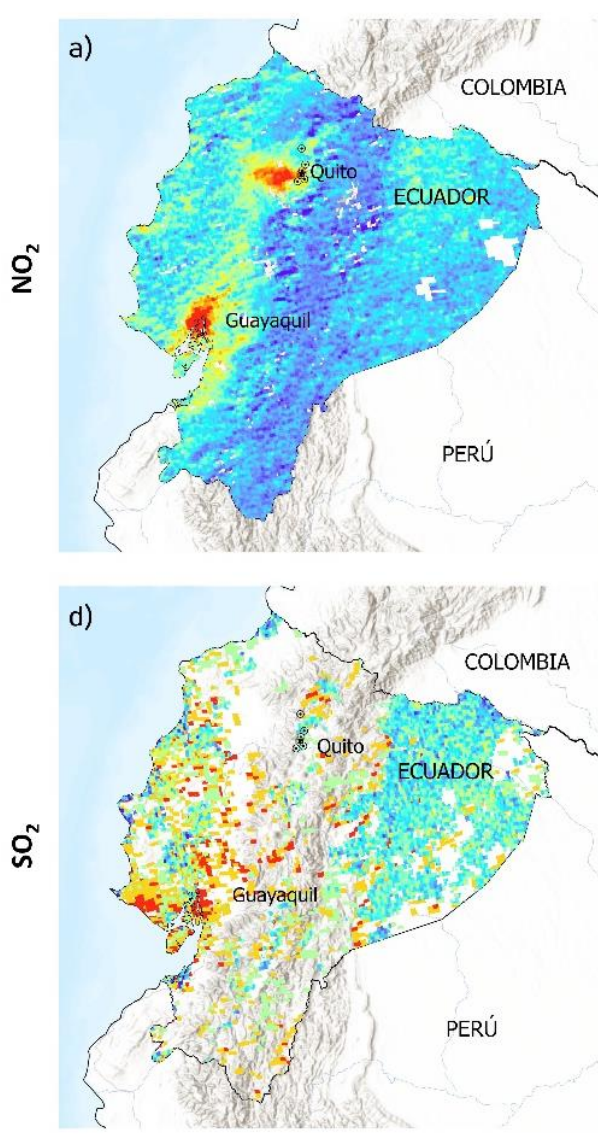

$16-22 / 03 / 2020$

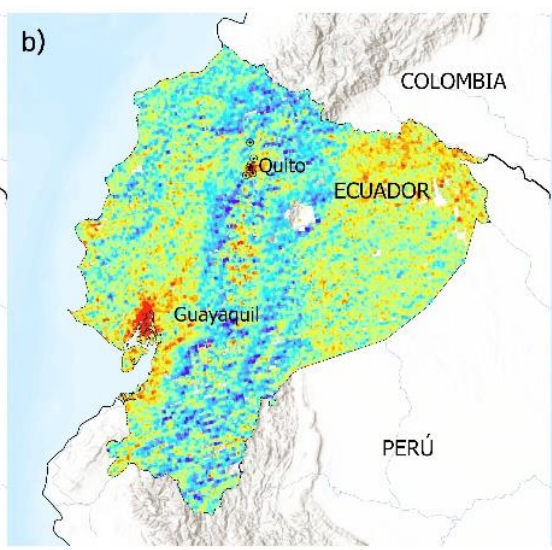

e)

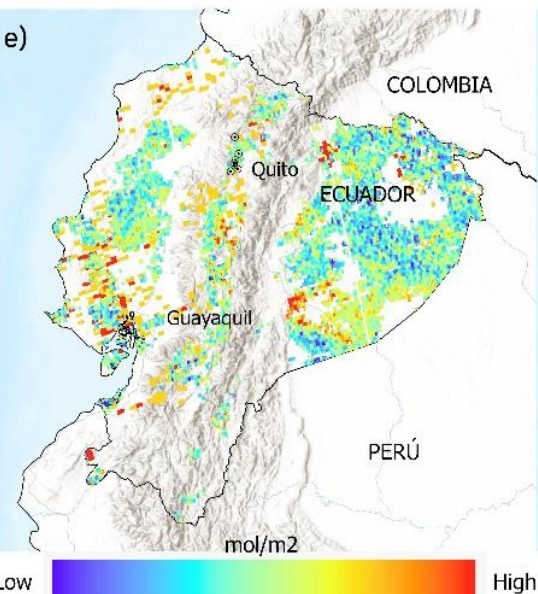

Low

High
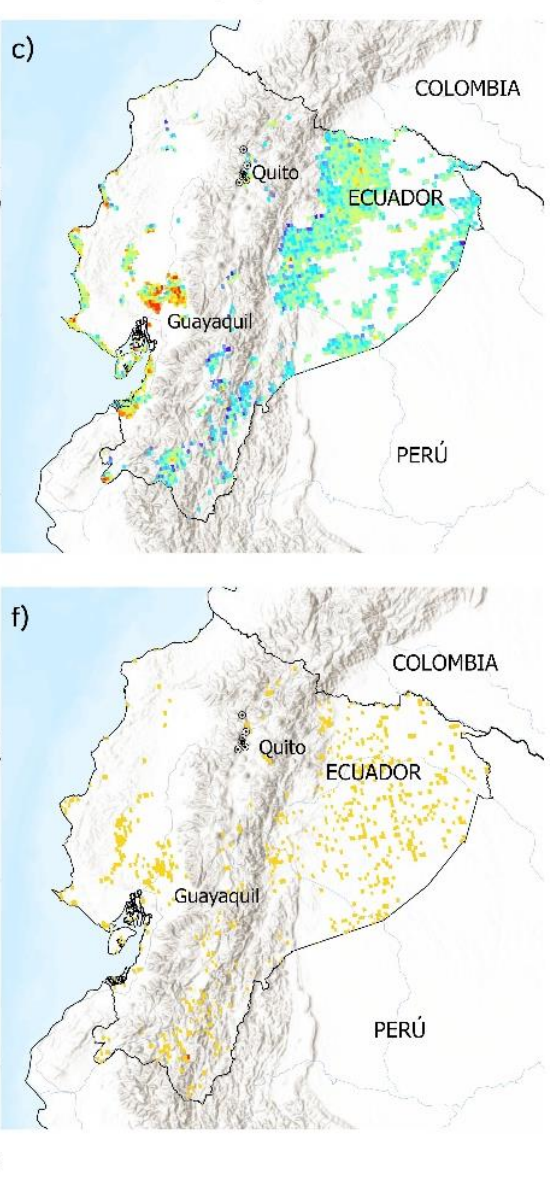

Fig. 4. Satellite images of $\mathrm{NO}_{2}(\mathrm{a}-\mathrm{b})$ and $\mathrm{SO}_{2}(\mathrm{~d}-\mathrm{-f})$ levels for Ecuador one week before the COVID-19 quarantine 09-15 March 2020 (a, d) and during the first week 16-22 March 2020 (b, e) and second week 23-30 March 2020 (c, f) of quarantine. 
activities. The same was seen in the studies by Zheng et al. (2019) and Wang et al. (2020), where $\mathrm{NO}_{2}$ change was reported due to the reduction of combustion activities, including transportation.

As discussed before (Section 4.1), the nationally mandatory measures were applied very efficiently in Quito from the first day of quarantine (March 17, 2020). However, it took about a week to completely shut down the activities in the similarly sized port city Guayaquil (Fig. 4). These differences were reflected in the $\mathrm{NO}_{2}$ and $\mathrm{SO}_{2}$ levels which decreased rapidly as epidemic isolation measures were implemented in Quito, but not as rapidly in Guayaquil (Fig. 4). This lag in the application of social distancing measures caused a rapid increase in COVID-19 cases in this port city, while the capital city had a much lower growth of infections. The higher number of cases in the port city may have considerable health implications, not only due to the spread of the disease, but also due to the poorer air quality, which is an aggravator of COVID-19 (Wu et al., 2020). There are some preliminary studies suggesting horrific statistics for Guayaquil, possibly the worst in the world to this date, highlighting the damage that this virus can do in developing world (Cabrera and Kurmanaev, 2020).

\section{CONCLUSIONS}

In this work the improvement of urban air quality due to the COVID-19 mitigation measures was investigated for the first time in a Latin American country. As the numbers of the COVID-19 infection cases started accelerating in Ecuador, a series of extremely strict quarantine measures, focused on social distancing and isolation, were progressively implemented in the country starting March 17, 2020. While these measures were immediately implemented in the capital city Quito, there were delays in full implementation in the port city Guayaquil due to public protests and disrespect of the rules.

The time series of the 24-hour data for $\mathrm{NO}_{2}, \mathrm{SO}_{2}, \mathrm{PM}_{2.5}$ and $\mathrm{CO}$ in seven sites in Quito during January 1-April 12, 2020 showed a clear reduction of pollutant concentrations during the four weeks of quarantine. The comparative fourweek analysis, before and during quarantine, exhibited one of the most significant globally reported reductions of $\mathrm{NO}_{2}$ $(-68 \%), \mathrm{SO}_{2}(-48 \%), \mathrm{CO}(-38 \%)$ and $\mathrm{PM}_{2.5}(-29 \%)$ during the first month of quarantine in Quito. This is a clear demonstration of the effect on urban air quality of extremely strict reduction in anthropogenic activities. Although implemented measures were gradually stricter, there was no steady decreasing trend in the measured pollutants. In addition, $\mathrm{PM}_{2.5}$ concentrations displayed more variability due to the variable and windy conditions associated with dust resuspension.

The spatial distribution maps identified the zones that are more affected by pollution reduction. Central areas of the city show the highest concentrations of $\mathrm{NO}_{2}$ and $\mathrm{CO}$ before and during the quarantine, although the levels are visibly reduced during the pandemic. The concentrations of $\mathrm{PM}_{2.5}$ also show the biggest reduction in the city outskirts in the industrial areas, and similarly, $\mathrm{SO}_{2}$ shows a large overall reduction, including the zone near the thermoelectric power plant.

Finally, comparative analysis of satellite data for Ecuador before and during the quarantine shows the differences in the spatial evolution of air pollution in relation with the implementation of the protective measures in the country. It can be noted that the $\mathrm{NO}_{2}$ and $\mathrm{SO}_{2}$ levels decreased rapidly in Quito and lagged in Guayaquil, due to the less efficient implementation of epidemic isolation measures. The lag in Guayaquil could have a considerable cost to the mortality rate in the port city, not only due to the spread of the disease, but also due to the poorer air quality in the port city.

\section{ACKNOWLEDGMENTS}

Funding for this study is provided by the Universidad de Las Americas, Ecuador as a part of an internal research project AMB.RZ.20.01.

\section{DISCLAIMER}

There are no real or perceived financial conflicts of interests for any author.

\section{REFERENCES}

Ban-Weiss, G.A., McLaughlin, J.P., Harley, R.A., Kean, A.J., Grosjean, E. and Grosjean, D. (2008). Carbonyl and nitrogen dioxide emissions from gasoline- and dieselpowered motor vehicles. Environ. Sci. Technol. 42: 3944-3950. https://doi.org/10.1021/es8002487

Cabrera, J.M.L. and Kurmanaev, A. (2020). Ecuador's death toll during outbreak is among the worst in the world. The New York Times. https://www.nytimes.com/2020/04/ 23/world/americas/ecuador-deaths-coronavirus.html

Chen, Q.X., Huang, C.L., Yuan, Y. and Tan, H.P. (2020). Influence of COVID-19 event on air quality and their association in Mainland China. Aerosol Air Qual. Res. 20: 1541-1551. https://doi.org/10.4209/aaqr.2020.05.0224

Cho, Y. (2020, February 24). Blue skies return to China as coronavirus cuts coal consumption. Nikkei Asian Review. https://asia.nikkei.com/Spotlight/Coronavirus/Blue-skiesreturn-to-China-as-coronavirus-cuts-coal-consumption

EMASEO (2011). Municipio del distrito metropolitano de Quito: Plan de Desarrollo 2012-2022. Quito.

European Space Agency (ESA) (2020). Coronavirus: nitrogen dioxide emissions drop over Italy. Satell. images video. https://youtu.be/ARpxtAKsORw

Faridi, S., Yousefian, F., Niazi, S., Ghalhari, M.R., Hassanvand, M.S. and Naddafi, K. (2020). Impact of SARS-CoV-2 on ambient air particulate matter in Tehran. Aerosol Air Qual. Res. 20. https://doi.org/10.420 9/aaqr.2020.05.0225

Filonchyk, M., Hurynovich, V., Yan, H., Gusev, A. and Shpilevskaya, N. (2020). Impact assessment of COVID19 on variations of $\mathrm{SO}_{2}, \mathrm{NO}_{2}, \mathrm{CO}$ and $\mathrm{AOD}$ over east China. Aerosol Air Qual. Res. 20: 1530-1540. https://doi.org/10.4209/aaqr.2020.05.0226

Gardiner, B. (2020, April 8). Pollution made COVID-19 worse. Now lockdowns are clearing the air. National 
Geographic. https://www.nationalgeographic.com/science/ 2020/04/pollution-made-the-pandemic-worse-but-lockd owns-clean-the-sky/

Instituto Nacional de Estadística y Censos (INEC) (2011). Poblacion, superficie (km2), densidad poblacional a nivel parroquial. Quito.

Lelieveld, J., Evans, J.S., Fnais, M., Giannadaki, D. and Pozzer, A. (2015). The contribution of outdoor air pollution sources to premature mortality on a global scale. Nature 525: 367-371. https://doi.org/10.1038/nature15371

Limb, M. (2016). Half of wealthy and $98 \%$ of poorer cities breach air quality guidelines. BMJ 353: i2730. https://doi.org/10.1136/bmj.i2730

Mahato, S., Pal, S. and Ghosh, K.G. (2020). Effect of lockdown amid COVID-19 pandemic on air quality of the megacity Delhi, India. Sci. Total Environ. 730: 139086. https://doi.org/10.1016/j.scitotenv.2020.139086

Menebo, M.M. (2020). Temperature and precipitation associate with Covid-19 new daily cases: A correlation study between weather and Covid-19 pandemic in Oslo, Norway. Sci. Total Environ. 737: 139659. https://doi.org/ 10.1016/j.scitotenv.2020.139659

Miller, B. (2015). 7 - Formation and control of acid gases, and organic and inorganic hazardous air pollutants. Fossil Fuel Emissions Control Technol. 2015: 327-365. https://doi.org/10.1016/B978-0-12-801566-7.00007-5

National Aeronautics and Space Administration (NASA) (2020). Airborne nitrogen dioxide plummets over China. https://earthobservatory.nasa.gov/images/146362/airbor ne-nitrogen-dioxide-plummets-over-china

Pani, S.K., Lin, N.H. and RavindraBabu, S. (2020). Association of COVID-19 pandemic with meteorological parameters over Singapore. Sci. Total Environ. 740: 140112. https://doi.org/10.1016/j.scitotenv.2020.140112

Park, G., Mun, S., Hong, H., Chung, T., Jung, S., Kim, S., Seo, S., Kim, J., Lee, J., Kim, K., Park, T., Kang, S., Ban, J., Yu, D.G., Woo, J.H. and Lee, T. (2019). Characterization of emission factors concerning gasoline, LPG, and diesel vehicles via transient chassis-dynamometer tests. Appl. Sci. https://doi.org/10.3390/app9081573

Pope, C.A. and Dockery, D.W. (2012). Health effects of fine particulate air pollution: lines that connect. J. Air Waste Manage. Assoc. 56: 709-742. https://doi.org/10.10 80/10473289.2006.10464485

Prata, D.N., Rodrigues, W. and Bermejo, P.H. (2020). Temperature significantly changes COVID-19 transmission in (sub)tropical cities of Brazil. Sci. Total Environ. 729: 138862. https://doi.org/10.1016/j.scitotenv.2020.138862

Safarian, S., Unnthorsson, R. and Richter, C. (2020). Effect of coronavirus disease 2019 on $\mathrm{CO}_{2}$ emission in the world. Aerosol Air Qual. Res. 20: 1197-1203. https://doi.org/10.4209/aaqr.2020.0.0151

Servicio Nacional de Gestion de Riesgos y Emergencias, (2020). Informe de Situación No. 019 COVID 19_25032020. Informes de Situación e Infografias COVID 19. https://www.gestionderiesgos.gob.ec/wpcontent/uploads/2020/03/Informe-de-Situaci\%C3\%B3nNo019-Casos-Coronavirus-Ecuador-25032020_17.pdf

Suhaimi, N.F., Jalaludin, J. and Latif, M.T. (2020).
Demystifying a possible relationship between COVID19, air quality and meteorological factors: evidence from Kuala Lumpur, Malaysia. Aerosol Air Qual. Res. 20: 1520-1529. https://doi.org/10.4209/aaqr.2020.05.0218

U.S. EPA (2018). Health and environmental effects of particulate matter (PM). https://www.epa.gov/pm-pollution/ health-and-environmental-effects-particulate-matter-pm

United Nations (UN) (2015). 2015 revision of world population prospects. United Nations. New York. https://www.un.org/development/desa/ageing/news/201 5/08/2015-revision-of-world-population-prospects/

United Nations (UN) (2019). World urbanization prospects: The 2018 revision. https://population.un.org/wup/CountryProfiles/

Veefkind, J.P., Aben, I., McMullan, K., Förster, H., de Vries, J., Otter, G., Claas, J., Eskes, H.J., de Haan, J.F., Kleipool, Q., van Weele, M., Hasekamp, O., Hoogeveen, R., Landgraf, J., Snel, R., Tol, P., Ingmann, P., Voors, R., Kruizinga, B., ... Levelt, P.F. (2012). TROPOMI on the ESA Sentinel-5 Precursor: A GMES mission for global observations of the atmospheric composition for climate, air quality and ozone layer applications. Remote Sens. Environ. 120: 70-83. https://doi.org/10.1016/j.rse.2011.0 9.027

Wang, P., Chen, K., Zhu, S., Wang, P. and Zhang, H. (2020). Severe air pollution events not avoided by reduced anthropogenic activities during COVID-19 outbreak. Resour. Conserv. Recycl. 158: 104814. https://doi.org/10. 1016/j.resconrec.2020.104814

World Health Organization (WHO) (2016, May 12). Air pollution levels rising in many of the world's poorest cities. http://www.who.int/mediacentre/news/releases/2 016/air-pollution-rising/en/\#.WrrLXYrQNwg.mendeley

Worldometer. (2020). Coronavirus Cases. COVID-19 coronavirus pandemic. https://www.worldometers.info/c oronavirus/?utm_campaign=homeAdvegas1?

Wu, X., Nethery, R.C., Sabath, M.B., Braun, D. and Dominici, F. (2020). Exposure to air pollution and COVID-19 mortality in the United States. medRxiv 2020.04.05.20054502 https://doi.org/10.1101/2020.04.0 5.20054502

Xu, K., Cui, K., Young, L.H., Hsieh, Y.K., Wang, Y.F., Wan, S. and Zhang, J. (2020). Air quality index, indicatory air pollutants and impact of COVID-19 event on the air quality near central China. Aerosol Air Qual. Res. 20: 1204-1221. https://doi.org/10.4209/aaqr.2020.04.0139

Xue, R., Wang, S., Li, D., Zou, Z., Chan, K.L., Valks, P., Saiz-Lopez, A. and Zhou, B. (2020). Spatio-temporal variations in $\mathrm{NO}_{2}$ and $\mathrm{SO}_{2}$ over Shanghai and Chongming Eco-Island measured by ozone monitoring instrument (OMI) during 2008-2017. J. Cleaner Prod. 258: 120563. https://doi.org/10.1016/j.jclepro.2020.120563

Zalakeviciute, R., Rybarczyk, Y., López-Villada, J. and Diaz Suarez, M.V. (2017). Quantifying decade-long effects of fuel and traffic regulations on urban ambient $\mathrm{PM}_{2.5}$ pollution in a mid-size South American city. Atmos. Pollut. Res. 9: 66-75. https://doi.org/10.1016/j.ap r.2017.07.001

Zalakeviciute, R., López-Villada, J. and Rybarczyk, Y. 
(2018a). Contrasted effects of relative humidity and precipitation on urban $\mathrm{PM}_{2.5}$ pollution in high elevation urban areas. Sustainability 10: 2064. https://doi.org/10.3 390/su10062064

Zalakeviciute, R., Buenaño, A., Sannino, D. and Rybarczyk, Y. (2018b). Urban air pollution mapping and traffic intensity: Active transport application, In Air pollution: Monitoring, quantification and removal of gases and particles, Del Real Olvera, J. (Ed.), IntechOpen, p. 13. https://doi.org/http://dx.doi.org/10.5772/57353
Zheng, Z., Yang, Z., Wu, Z. and Marinello, F. (2019). Spatial variation of $\mathrm{NO}_{2}$ and its impact factors in China: An application of sentinel-5P products. Remote Sens. 11: 1939. https://doi.org/10.3390/rs11161939

Received for review, May 23, 2020

Revised, June 29, 2020

Accepted, June 5, 2020 